\title{
Young Children's Mental Health: Impact of Social Isolation During The COVID-19 Lockdown and Effective Strategies
}

\author{
Angel Urbina-Garcia, $\mathrm{PhD}$ \\ University of Hull \\ *Correspondence should be addressed to Angel Urbina, School of Education and Social Science, University of \\ Hull, HU6 7RX, United Kingdom. Email: M.Urbina-Garcia@hull.ac.uk
}

\begin{abstract}
The rapid spread of the COVID-19 has triggered a worldwide epidemic emergency which is an international concern given that it poses several challenges to physical and mental health of humans across the globe. The declaration of "pandemic" by the WHO led governments to put in place strategies to stop the spread of the virus; most significantly, enforced lockdown and social isolation. Like businesses and universities, schools around the world have been closed and children must remain at home during this pandemic. However, social isolation could have a negative impact on young children's wellbeing and if not addressed properly, it could trigger long-term negative effects in their mental health. While social isolation has proven useful to stop spreading the virus, social epidemiology research shows that comorbidity of physical illnesses and mental disorders is higher especially in the absence of positive social relationships. Psychological studies show that social isolation could trigger several complications including emotional disturbance, sleep disorders, depressive syndromes, anxiety and stress. However, little is known about the psychological impact of social isolation during COVID-19 on young children's mental health and to date, there are no specific guidelines regarding effective psychological strategies that could support children's wellbeing. Drawing form existing research on social isolation, this review aims to synthesise previous literature to explore the negative impact of social isolation in young children and offer a comprehensive set of evidenceinformed recommendations for parents and professionals to safeguard the mental health of young children currently on lockdown across the globe.
\end{abstract}

\section{Keywords:}

Social isolation; COVID-19; Children's Wellbeing; Children's Mental Health; Socioemotional wellbeing. 


\section{Introduction and background}

In March 2020 the World Health Organisation (WHO) declared a worldwide pandemic due to the spread of a novel virus known as SARS-CoV-2, which started in Wuhan (China) and which abruptly spread across the world (Nishiura, 2020). SARS-CoV-2 spreads by direct contact and, there has been a rapid and dangerous daily increase in the number of infections around the world. This has led governments to take specific measures to stop the spread of the virus (CDC, 2020). According to the latest figures from Johns Hopkins University (2020), as of May 5, 2020 there are 3,606,038 confirmed cases with 252,151 deaths around the world. Undoubtedly, this is a deadly virus which threatens not only the physical, but also psychological health of human beings. As a result, governments have put in place public health emergency measures to reduce the spread of the virus such as encouraging the use of protective eyewear, gloves and facemasks (Wang et al., 2020). Other restrictions include lockdown, social distancing and the closure of universities, businesses and schools -measures, which research shows, could negatively impact psychological health (von Bortel, 2016). Understandably, most of the efforts in research (e.g., recently published scientific literature focuses on vaccinations and physical health overall) and practice (e.g., ensuring they have the adequate equipment) during the current emergency, are focused on healthcare workers. However, little attention has been paid to the extent to which social isolation could impact young children's mental health who are currently isolated at home. To date, there are no specific evidence-informed guidelines regarding effective strategies that adults could use to support children's socioemotional wellbeing during a lockdown during a pandemic like the one we are currently facing. Drawing from existing research on social isolation, this review aims to synthesise previous literature to explore the negative impact that social isolation could have in children and offer a comprehensive set of evidence-informed recommendations for parents and professionals to safeguard the socioemotional well-being of children.

\section{Socioemotional development in young children}

Socioemotional skills are necessary for the development of children's relationships (Isaacs, 2013) and occur in a context with parents, siblings and relatives (Feldman, 2015). In this way, they can express and communicate their needs, interests and ideas which helps them establish meaningful relationships and emotional connections with their most significant adults (Feldman, 2012). Emotional development in young children includes the extent to which a child is able to experience, recognise, categorise, name and regulate his/her own emotions (Stoica \& Roco, 2013) which in turn, also helps them to regulate behaviours in different situations (Schunk \& Zimerman, 2012). Developing emotional skills is of utmost importance as it helps children recognise emotions in others (Dowling, 2014). This is of relevance since this will allow the child to develop a sense of empathy - which is a necessary skill when living and coexisting within a social group (Masterson \& Kersey, 2013). From a developmental psychology perspective, it is well known that social skills and emotional skills (henceforth referred to as socioemotional), are indeed distinct, but both sets of skills coexist and support the development of each other (Schonert et al., 2015). The interrelation of socioemotional skills and well-being (socioemotional wellbeing), assumes a "stable state that indicates the emotional evaluation, positive or negative that an individual makes of the results of the totality of his/her interactions" (Bericat, 2014, p. 606). With this in mind, positive social interactions are fundamental to promoting socioemotional wellbeing. A fundamental element here is the need to listen to children's experiences as an effective strategy to promote and establish empathetic and meaningful relationships with adults (Erskine, Moursund \& Trautmann, 2013).

Children's views are widely ignored by their parents (Urbina-Garcia, 2019), but there is evidence that when children's needs, interest and ideas are attended to they feel important and valued, and this may have an important positive impact on their socioemotional well-being (Betz et al., 2013; UrbinaGarcia, 2019). Creating opportunities to listen to children's views seems to improve parent-child interactions (Shire, Galsrud \& Kasari, 2016). Positive parent-child involvement promotes children's cognitive, social, and emotional well-being (Flouri \& Buchanan, 2004; Kazura, 2000; Parke, 2004; Tamis-LeMonda et al., 2004). When adults listen to children, children feel understood, loved, valued and more importantly safe -especially in stressful situations (Dacey et al., 2016). Listening to children 
seems to be an essential strategy if we aim to promote their socioemotional well-being. By definition, socioemotional wellbeing is developed within the inherent context of social interactions. For a child, this means that the interaction not only with mum and dad, but also with cousins, school friends and acquaintances from the neighbourhood, are paramount for the young child to develop his/her socioemotional wellbeing (Hastings, Miller \& Troxel, 2015; Thomson \& McLanahan, 2012), which otherwise, would not be possible to develop -if isolated for example. Current measures such as social isolation may jeopardise children's well-being since children's interactions could be potentially limited during the current lockdown (Cacioppo \& Cacioppo, 2014). Feelings of despair, uncertainty, sadness or insecurity may arise as a result of the limited physical interaction with others when isolated (Cacioppo \& Cacioppo, 2014; Caciopo \& Patrick, 2008) in addition to triggering a range of behaviours which children under normal circumstances (i.e., without a pandemic), would not display. However, it is important to note that children could still have an "interaction" with their neighbourhood friends, school peers, relatives and so forth throughout the use of technology. This will be further discussed in the recommendations section.

\section{Research on Social Isolation}

Drawing from biological research, humans seem to be fundamentally a social species who need to recognise and form relationships with others for survival (Bowles \& Gintis, 2013; Tomasello \& Vaish, 2013). A vast body of research has shed light on the way in which social relationships positively impact mental well-being in humans throughout different stages of the lifespan (Cacioppo \& Cacioppo, 2014; Haslam, Jetten \& Alexander, 2012; Holt-Lunstad \& Smith, 2012; Huxhold, Fiori \& Windsor, 2013; Seppala, Rossomando \& Doty, 2013), with other studies showing the negative outcomes of the lack or absence of social relationships (Santini et al., 2015). While social isolation could be regarded as a socially constructed concept, it can indeed be, quantifiable and observable (Holt-Lunstad, Smith \& Baker, 2015). Loneliness, on the other hand, is defined as the perception of social isolation. That is to say, the subjective experience of the individual of perceiving himself/herself lonely (Holt-Lunstad, Smith \& Baker, 2015). However, it is important to highlight the major role that an individual's cognitions play as a mediator in which an individual could prefer to be alone and still feel happy and connected, whereas another individual could be surrounded by relatives and friends and still feel lonely. As a result, there is evidence to suggest that these two concepts are not significantly correlated and could act as independent variables (Coyle \& Dugan, 2012; Perissinotto \& Covinsky, 2014). Nevertheless, there is no agreement across disciplines as to the best way to define and measure these concepts (Courtin \& Knapp, 2017). Other scholars define social isolation as the "disengagement from social ties, institutional connections or community participation" (Pantell et al., 2013. p. 2056), which seems to be very much in line with the idea currently being used by governments around the world during the COVID-19. In this review, we follow the idea of Pantell and colleagues about social isolation. We also consider the role of perception in individuals to maximise a rapid -but importantly necessaryanalysis of existing evidence about the way in which physical isolation and the perception of being lonely impact mental health -more specifically that of young children.

Social epidemiology research shows that comorbidity of physical illnesses and mental disorders is higher especially in the absence of positive social relationships (Cacioppo \& Cacioppo, 2014). On the other hand, psychological studies show that social isolation can trigger several complications including emotional disturbance, sleep disorders, depressive syndromes, anxiety, stress and burnout (Holt-Lunstad, Smith \& Baker, 2015; Mushtaq et al., 2014). Research in the psychological field has shown that social isolation can trigger feelings of uncertainty, fear and despair (Hawryluck et al., 2004; Shultz et al., 2016). These feelings seem to be usual when in presence of a life-threatening event such as a deadly virus. For example, during and after the outbreak of Ebola in West Africa in 2013, studies revealed that higher levels of stress and anxiety were experienced by members of the society (Shultz et al., 2016). During the outbreak of swine flu H1N1, up to $30 \%$ of general public reported to be extremely anxious about contracting the virus (Rubin, Potts \& Michie, 2010). Recent research shows that fear of infections, boredom, feelings of frustration and length of lockdown may trigger serious psychological distress (Brooks et al., 2020), and lockdown could lead to anxiety, obsessive or delusional thoughts and cognitive rumination in vulnerable subjects (Mucci, Mucci \& Diolaiuti, 2020). Research on social isolation also shows that premature mortality is increased when people feel unhappy with their social 
relations or are socially isolated (Holt-Lunstad, Smith \& Baker, 2015), in addition to experiencing low self-esteem (Steptoe, Owen \& Kunz-Ebrecht, 2004), low self-efficacy (Valtorta et al., 2016), high blood-pressure and a diminished immune functioning (Grant, Hamer \& Steptoe, 2009; Hawkley et al., 2010).

\section{Social Isolation and its Impact on Young Children's Socioemotional wellbeing}

Human beings are eminently social species and adults need social interactions just like young children. Social interactions are needed not only to help children learn cultural values (Brown et al., 2019), social norms or socially accepted behaviours (Staub, 2013), but also to help children develop their socioemotional wellbeing which plays a major role in developing long-lasting and meaningful relationships with other children and adults (Meins, 2013). From a developmental perspective, socialization in the early stages of life are paramount since they have shown to have long-term impact across the lifespan not only regarding the socioemotional domain, but also cognitive and physical domains (Isaacs, 2013). Children, just like adults, need to have positive social interactions to help them develop a healthy socioemotional well-being, given that the lack or absence of such social interactions could jeopardise children's wellbeing. Drawing from research on social isolation it is possible that children, during the current lockdown, could show several some of the following signs and symptoms. It is possible that they could develop feelings of sadness or insecurity (Hawkley \& Capitanio, 2015), anger (Biordi \& Nicholson, 2013) frustration or boredom (Brooks et al., 2020). Children may show disruptive behaviours (Bosch \& Young, 2017) and sleep disturbances (Simon \& Walker, 2018). Children could develop high levels of stress as a result of high levels of cortisol derived from facing another day of "danger" because of the pandemic (Steptoe, \& Kivimäki, 2012). Children could develop early signs of anxiety derived from a constant worrying -via cognitive rumination (Teo, Lerrigo \& Rogers, 2013 ) to avoid catching the virus (Ren, Gao \& Chen, 2020), or even depressive symptoms derived from a constant state of sadness, low-mood or lack of motivation (Sanders, 2020). They can also wet the bed or have nightmares, be more clingy or more naughty (BPS, 2020). Children may change their eating patterns (Stankovska, Memedi \& Dimitrovsky) or show no or little interest in talking (Rubin, Asendorpf \& Asendorpfz, 2014). Interestingly, research shows that these signs and symptoms could have a negative impact on children's self-esteem (Watson \& Nesdale, 2012) and self-efficacy (Ahmad, Yasien \& ahmad, 2014) which in turn, have the potential to weakening the immune system (Kiecolt-Glaser et al., 2002; Segerstrom \& Miller, 2004). Taken together, research has clearly shed light on the negative impact that the absence of social interaction could have in children's socioemotional well-being. While some children may find less difficulties facing situations like this one (i.e., they have more skills already developed regarding problem solving, decision making, emotional self-regulation among others), other children may struggle more given the limited skills they have developed so far.

\section{Evidence-based Recommendations: Supporting Young Children's Socioemotional Well-being}

While the above signs and symptoms can be observed in children during the current situation, it is important to acknowledge the role of other variables which could mediate such impact including but not limited to cognitive coping strategies (Evans et al., 2015), the quality of the parent-child interaction (Hembree-Kigin \& McNeil, 2013), media exposure and the knowledge children have about the current situation among others. While analysing these mediators is out of the scope of the present study, specific recommendations can be drawn from existing evidence on social isolation. Firstly, it is important to keep in mind that children will use their cognitive resources (e.g., previous experiences, knowledge and information, social relationships, emotional connections with significant adults) to make sense of their world by interpreting the events around them (Messina \& Zavattini, 2014; Stern, 2018). Secondly, it is important to support young children in different ways bearing in mind the need to make them feel secure and by giving them developmentally appropriate information that they can use to understand and face the current situation. Needless to say, one of the main strategies to achieve this, is the need to listen to children's perspectives (Urbina-Garcia, 2019) with a view to obtaining a more accurate understanding of how they are interpreting and thus, experiencing the current situation. This could also be a medium through which adults can successfully help children implement cognitive, emotional and behavioural changes to support their socioemotional well-being. This could work as an essential baseline to implement further strategies. The following set of strategies aim to support adults, caregivers, teachers, parents, child psychologists and other professionals to help young children 
navigate through the current situation to support children's socioemotional well-being and to avoid further negative impact.

Identify and recognise own emotions. Life-threatening situations may make both children and adults feel scared and insecure, and unfortunately (or fortunately), research has shown that children perceive how adults feel, thus triggering similar feelings (Pelini, 2019). Based on current evidence, it is important that adults take some time to identify, recognise, label and self-regulate the wide range of emotions the current situation triggers with a view to helping children manage theirs. By recognising one's own emotions, adults are in a better position to model children how to name, identify and regulate their own emotions. Research on social learning (Rosenthal \& Zimmerman, 2014), also suggests that children learn by observing people around them. The current situation could be used as a powerful learning opportunity to model children how to recognise and manage emotions as well as to modify thinking patterns.

Help children understand how they feel and to share their feelings. Research on socioemotional well-being shows that an essential step to helping children control their own emotions is through the identification and recognition of the emotions experienced (Meyer et al., 2014). Feeling scared, stressed, anxious or nervous are normal psychological and biological responses to life-threatening situations. (Crescentini, 2016). Children are learning how to label what they feel; hence, adults should support this new learning by engaging in warm and respectful conversations with the child with a view to helping accept, identify and value their emotions. This will have a positive impact on the parent-child interaction which will strengthen children's self-esteem and self-confidence.

Give your child voice where you can: Research shows that under stressful circumstances, children may have different things to say about the way in which they see and perceive social situations, however, there seems to be some empirical evidence that shows that adults do not tend to listen to children's views in a systematic way (Urbina-Garcia, 2019). Adults should ask questions to children to explore their only what they know, but also how they feel during this situation. Adults should open spaces and create situations where they can listen to children's versions of the event and how they are living the current situation at home. By doing this, adults could explore how children are constructing their own version which will allow parents to offer more accurate information to ease a child's anxiety, fear or sadness. In this way, children will feel valued and that their views are important and considered at home.

Children need to feel safe and secure: A life-threatening event will trigger feelings of fear or despair which would prompt children to feel insecure (Cacioppo \& Cacioppo, 2014; Caciopo \& Patrick, 2008). Adults should ensure that children know that they are safe and that this event is temporary. In this way, children will feel confident and protected which will decrease the likelihood of feeling negative emotions and will help create a stronger emotional relationship with adults (Erskine, Moursund \& Trautmann, 2013).

Observe changes in your child's behaviour: An indication of how a child is dealing and coping with a stressful situation may relate to changes in children's behaviour (Cohen et al., 2013). Previous evidence suggests that such changes, are expected behavioural reactions which could indicate children's attempts to understand and deal with an unfamiliar situation (Hirvonen et al., 2013; Yeo et al., 2014). Adults should pay attention to such behavioural changes and engage in a warm and respectful conversation to accept and validate such changes. As a result, children will know that this is normal, and that adults are there to understand and support them.

Keep routines in place: Research from developmental psychology reveals that young children need a clear structure in their lives (Isaacs, 2013). Adults usually help children understand and learn when they can play, go to school, have a family dinner or go to bed (Graham \& Reynolds, 2013), however under stressful events, children may show behavioural changes which may not allow them to follow the usual routine. Parents must help children keep the normal routine at home as much as possible. However, adults can also be flexible and make a few changes to the routine. 
With this, children will know that routines are still in place but will learn that routines can also be flexible. Adults could enhance children's sense of belonging by involving children in homedecisions and activities (e.g., breakfast time, home-schooling time, play time, dinner time). This will make children feel important, that they have a "voice" and that they are valued members of the family.

Keep a positive attitude: Facing stressful situations could trigger catastrophic thinking (i.e., a tendency to think the worst that could happen in every situation) in adults and children as a result of the limited resources persons can have when facing a threatening situation (Dacey et al., 2016). Adults and children could develop a tendency to see everything negative because they feel threatened. While this could be regarded as a "normal" reaction, adults should try to change this and employ positive thinking so that they can model it to children. Adults should make every effort to reassure children by letting them know that they are safe, that this just a temporary situation and that there are positive things about spending more time together. As a result, children will learn how to see the positive side of spending more time with family members and will help reduce a child's anxiety, fear or stress.

Create a loving and caring environment: Child psychology research shows that home environment has a direct positive influence on children's socioemotional development (Gottfried, 2013), when intrafamily relationships are based on understanding, love and acceptance (Thomson \& McLanahan, 2012). At all times, adults should make efforts to create a loving, caring and safe environment for children by respecting the different perspectives of family members, engaging in warm and respectful conversations and by making all members -specially young children- active participants in decisions and activities at home. This will strengthen children's sense of belonging, make them feel secure and valued (Betz et al., 2013; Urbina-Garcia, 2019) and will strengthen their socioemotional well-being.

Monitor or limit media exposure: Young children -just like adults- react differently to the information around the current situation which could be greatly influenced by their exposure to media (Gentile et al., 2014). Media (e.g., TV or radio) and social media (e.g., internet-based social networks) have been found to greatly influence children's mood, emotions and behaviours (Chassiakos et al., 2016). Young children will try to use their cognitive resources (e.g., knowledge and information, social relationships, emotional connections with significant adults) to make sense of their world by interpreting the events around them (Gammage, 2012). Adults should limit the consumption of news and regulate the information children are exposed to since this could trigger feelings of fear or sadness or even depressive symptoms (Mushtaq et al., 2014; Sanders, 2020). This will allow adults to identify and control the information children are watching/reading and offer more developmentally appropriate information to support children's understanding of the situation. Adults should also reassure children and make them feel secure by giving them developmentally appropriate information that they can use to understand and face the current situation. This will make children feel secure and supported by their loved ones.

Take care of your own mental health: Research has shown that parents' mental health can directly influence their children's (van Ee, E. Kleber \& Mooren, 2012). For instance, when adults are enjoying a given activity and/or feel happy, children can perceive such states and fell happy too, however the opposite is also true (Rimm, 2008). It has been documented that when adults are highly stressed or anxious, children start becoming stressed and anxious too (Woodruff-Borden et al., 2002). Adults should pay attention to their own mental health to tackle and attend any potential mental health-related problem (e.g., if continuously feeling scared, depressed or anxious for example) which could negatively impact young children's well-being. Adults may also need mental health support and should seek assistance of professional services.

Stay in touch virtually: Research reveals that under stressful circumstances, a person's social support network (e.g., talking to relatives, close friends, co-workers) is fundamental to successfully manage such circumstances (Lefrancois, et al., 2000). Social isolation does not mean that adults and children cannot interact with their social support network with the use of technology. Adults should create opportunities for children (and for themselves) where virtual meetings take place. This will allow to 
share experiences and the way in which different persons of the network are dealing with the situation. By sharing one's feelings (e.g., children and adults) and learning from other perspectives, children (and adults) may feel relieved and may learn, that they are not alone in this situation.

Model appropriate coping behaviours: Following the principles of the Social Learning Theory (Bandura \& Walters, 1977), adults play a major role in modelling behaviours which can be learnt by children. Adults can help children develop appropriate coping behaviours by engaging in activities such as listening to music (Goldbeck \& Ellerkamp, 2012), reading together, playing board games (Li et al, 2016) or muscle relaxation (Lohaus \& Klein-Hessling, 2003). This will help children learn new skills they did not have in their repertoire that could help them feel less stressed or anxious.

Understanding the difference between social distancing and physical distancing: Physical distancing is the epidemiological-related strategy that governments put in place to stop the spread of the virus since it can travel from one person to another by close physical proximity, however, the term social distancing may have been misunderstood. Adults should be aware of the need to differentiate these terms and avoid using social distancing in order not to discourage vital social interaction. Social interaction can still take place with the use of technology while avoiding physical proximity.

\section{Discussion and Conclusions}

To our knowledge, there is no study that offers specific strategies that adults could use to support children's socioemotional wellbeing during the lockdown of a pandemic like the one we are currently facing with COVID-19. This represents the first study to synthesise research on social isolation to identify how social isolation during the current pandemic, can jeopardise children's socioemotional well-being. Social isolation could lead to various psychological-related disorders if left unattended. Based on the review of the scientific literature, this study proposed a set of evidenceinformed effective strategies adults can use to support children during the current pandemic. This review revealed that there are serious implications for children's well-being at a psychological, behavioural and emotional level if children are socially isolated. It is possible that children could feel sadness, anger, frustration, fear or despair. Children could display disruptive behaviours, sleep disturbances, a sudden or gradual change in their eating patterns or show no or little interest in talking. Children can get stressed, anxious or show depressive symptoms which could be potentiated if parents are stressed and anxious. These signs and symptoms can have a negative impact on children's selfesteem, their sense of self-efficacy and their self-concept which in turn, can have an impact on their immune system.

The development of socioemotional wellbeing is paramount to children's development which can have positive mid-term and long-term effects across the lifespan, hence, efforts must be made to ensure that adults safeguard children's well-being to counteract the potential harm of social isolation. Adults are also likely to experience the negative effects of social isolation and should seek assistance when needed. Adults should reflect upon and understand the way in which the current pandemic is also affecting them so that they can manage the situation at home and thus model self-regulating strategies to children. People may think of feeling lonely and abandoned, however technology should be used to maintain social interaction with the significant others. The absence of social interaction (i.e., either objective or subjective social isolation) triggers self-preservation mechanisms at psychological, social and biological level to counteract the effects of social isolation, however there is evidence to suggest that this may take a toll on children's well-being in the long-term. Despite these strengths, there are some limitations that should be noted. First, this review did not follow the usual protocol of a systematic review given the urgency of the current pandemic and the need to offer the public, evidence-informed strategies to avoid any harm on children's mental health. Second, there is possible bias in the selection of studies as a result of not following the protocol for systematic reviews, however there seems to be strong evidence to support the notion that social isolation can be dangerous in the long-term. Caregivers, professionals, parents and caregivers in general, should be aware of the negative consequences of social isolation and able to use effective strategies to ameliorate the negative impact on children's mental health. 


\section{References}

Ahmad, Z. R., Yasien, S., \& Ahmad, R. (2014). Relationship between perceived social self-efficacy and depression in adolescents. Iranian journal of psychiatry and behavioral sciences, 8(3), 65.

Bandura, A., \& Walters, R. H. (1977). Social learning theory (Vol. 1). Englewood Cliffs, NJ: Prentice-hall.

Bericat, E. (2014). The socioemotional well-being index (SEWBI): Theoretical framework and empirical operationalisation. Social indicators research, 119(2), 599-626.

Betz, C. L., Lobo, M. L., Nehring, W. M., \& Bui, K. (2013). Voices not heard: A systematic review of adolescents' and emerging adults' perspectives of health care transition. Nursing Outlook, 61(5), 311336.

Biordi, D. L., \& Nicholson, N. R. (2013). Social isolation. Chronic illness: Impact and intervention, 85-115.

Bosch, O. J., \& Young, L. J. (2017). Oxytocin and social relationships: from attachment to bond disruption. In Behavioral Pharmacology of Neuropeptides: Oxytocin (pp. 97-117). Springer, Cham.

Bowles, S., \& Gintis, H. (2013). A cooperative species: Human reciprocity and its evolution. Princeton University Press.

British Psychological Society (BPs) (2020). Advice for Keyworkers Parents: Helping your child to changes due to the Covid-19 pandemic. Retrieved from https://www.bps.org.uk/sites/www.bps.org.uk/files/Policy/Policy\%20$\% 20$ Files/Advice\%20for\%20keyworker\%20parents\%20-\%20helping\%20your\%20child\%20adapt.pdf

Brooks, S. K., Webster, R. K., Smith, L. E., Woodland, L., Wessely, S., Greenberg, N., \& Rubin, G. J. (2020). The psychological impact of quarantine and how to reduce it: rapid review of the evidence. The Lancet.

Brown, E., Chen, D., Davies, I., Urbina Garcia, A., \& Munguia Godinez, I. (2019). Educating young people about society in China, England, Mexico and Spain: similar approaches to values education from different contexts. Compare: A Journal of Comparative and International Education, 1-17.

Cacioppo, J. T., \& Cacioppo, S. (2014). Social relationships and health: The toxic effects of perceived social isolation. Social and personality psychology compass, 8(2), 58-72.

Cacioppo, J. T., \& Patrick, B. (2008). Loneliness: Human Nature and the Need for Social Connection. New York: W. W. Norton \& Company.

Chassiakos, Y. L. R., Radesky, J., Christakis, D., Moreno, M. A., \& Cross, C. (2016). Children and adolescents and digital media. Pediatrics, 138(5),

Cohen, S., Evans, G. W., Stokols, D., \& Krantz, D. S. (2013). Behavior, health, and environmental stress. Springer Science \& Business Media.

Courtin, E., \& Knapp, M. (2017). Social isolation, loneliness and health in old age: a scoping review. Health \& social care in the community, 25(3), 799-812.

Coyle, C. E., \& Dugan, E. (2012). Social isolation, loneliness and health among older adults. Journal of Aging and Health, 24, 1346-1363.

Crescentini, C., Chittaro, L., Capurso, V., Sioni, R., \& Fabbro, F. (2016). Psychological and physiological responses to stressful situations in immersive virtual reality: Differences between users who practice mindfulness meditation and controls. Computers in Human Behavior, 59, 304-316. 
Dacey, J. S., Mack, M. D., \& Fiore, L. B. (2016). Your anxious child: How parents and teachers can relieve anxiety in children. John Wiley \& Sons.

Dowling, M. (2014). Young children's personal, social and emotional development. Sage.

Erskine, R., Moursund, J., \& Trautmann, R. (2013). Beyond empathy: A therapy of contact-in relationships. Routledge.

Evans, L. D., Kouros, C., Frankel, S. A., McCauley, E., Diamond, G. S., Schloredt, K. A., \& Garber, J (2015). Longitudinal relations between stress and depressive symptoms in youth: Coping as a mediator. Journal of abnormal child psychology, 43(2), 355-368.

Feldman, R. (2012). Parent-infant synchrony: A biobehavioral model of mutual influences in the formation of affiliative bonds. Monographs of the Society for Research in Child Development, 77(2), 42-51.

Feldman, R. (2015). The adaptive human parental brain: implications for children's social development. Trends in neurosciences, 38(6), 387-399.

Flouri, E. and Buchanan, A. (2004), 'Early Fathers and Mother's Involvement and Child's Later Educational Outcomes', British Journal of Educational Psychology, 86, 6-23.

Gammage, P. (2012). Children and schooling. Routledge.

Gentile, D. A., Reimer, R. A., Nathanson, A. I., Walsh, D. A., \& Eisenmann, J. C. (2014). Protective effects of parental monitoring of children's media use: A prospective study. JAMA pediatrics, 168(5), 479-484.

Goldbeck, L., \& Ellerkamp, T. (2012). A randomized controlled trial of multimodal music therapy for children with anxiety disorders. Journal of Music Therapy, 49(4), 395-413.

Gottfried, A. W. (Ed.). (2013). Home environment and early cognitive development: Longitudinal research. Academic Press.

Graham, P., \& Reynolds, S. (Eds.). (2013). Cognitive behaviour therapy for children and families. Cambridge University Press.

Grant, N., Hamer, M., \& Steptoe, A. (2009). Social isolation and stress-related cardiovascular, lipid, and cortisol responses. Annals of Behavioral Medicine, 37, 29-37.

Haslam, C., Jetten, J., \& Alexander, S. H. (2012). The social cure: Identity, health and well-being. Psychology press.

Hastings, P. D., Miller, J. G., \& Troxel, N. R. (2015). Making good: The socialization of children's prosocial development.

Hawkley, L. C., \& Capitanio, J. P. (2015). Perceived social isolation, evolutionary fitness and health outcomes: a lifespan approach. Philosophical Transactions of the Royal Society B: Biological Sciences, 370(1669), 20140114.

Hawkley, L. C., Preacher, K. J., \& Cacioppo, J. T. (2010). Loneliness impairs daytime functioning but not sleep duration. Health Psychology, 29, 124-129.

Hembree-Kigin, T. L., \& McNeil, C. B. (2013). Parent—child interaction therapy. Springer Science \& Business Media. 
Hirvonen, R., Aunola, K., Alatupa, S., Viljaranta, J., \& Nurmi, J. E. (2013). The role of temperament in children's affective and behavioral responses in achievement situations. Learning and Instruction, 27, 21-30.

Holt-Lunstad, J., Smith, T. B., Baker, M., Harris, T., \& Stephenson, D. (2015). Loneliness and social isolation as risk factors for mortality: a meta-analytic review. Perspectives on psychological science, 10(2), 227-237.

Huxhold, O., Fiori, K. L., \& Windsor, T. D. (2013). The dynamic interplay of social network characteristics, subjective well-being, and health: The costs and benefits of socio-emotional selectivity. Psychology and Aging, 28(1), 3.

Isaacs, S. (2013). Social development in young children (Vol. 20). Routledge.

Kazura, K. (2000). Fathers' qualitative and quantitative involvement: An investigation of attachment, play, and social interactions. The Journal of Men's studies, 9(1), 41-57.

Kiecolt-Glaser, J. K., McGuire, L., Robles, T., \& Glaser, R. (2002). Psychoneuroimmunology: Psychological influences on immune function and health. Journal of Consulting and Clinical Psychology, 70, 537547.

Lefrancois R., Leclerc G., Hamel S. \& Gaulin P. (2000) Stressful life events and psychological distress of the very old: does social support have a moderating effect? Archives of Gerontology and Geriatrics 31 (3), 243-255.

Li, W. H., Chung, J. O. K., Ho, K. Y., \& Kwok, B. M. C. (2016). Play interventions to reduce anxiety and negative emotions in hospitalized children. BMC pediatrics, 16(1), 36.

Lohaus, A., \& Klein-Hessling, J. (2003). Relaxation in children: Effects of extended and intensified training. Psychology and Health, 18(2), 237-249.

Masterson, M. L., \& Kersey, K. C. (2013). Connecting children to kindness: Encouraging a culture of empathy. Childhood Education, 89(4), 211-216.

Meins, E. (2013). Security of attachment and the social development of cognition. Psychology press.

Messina, S., \& Zavattini, G. C. (2014). How do children make sense of their experiences? Children's memories of wellbeing and distress from an attachment perspective. International Journal of Behavioral Development, 38(3), 209-218.

Meyer, S., Raikes, H. A., Virmani, E. A., Waters, S., \& Thompson, R. A. (2014). Parent emotion representations and the socialization of emotion regulation in the family. International Journal of Behavioral Development, 38(2), 164-173.

Mushtaq, R., Shoib, S., Shah, T., \& Mushtaq, S. (2014). Relationship between loneliness, psychiatric disorders and physical health? A review on the psychological aspects of loneliness. Journal of clinical and diagnostic research: JCDR, 8(9), WE01.

Nishiura, H. The Rate of Underascertainment of Novel Coronavirus (2019-nCoV) Infection: Estimation Using Japanese Passengers Data on Evacuation Flights. J. Clin. Med. 2020, 9, 419.

Pantell, M., Rehkopf, D., Jutte, D., Syme, S. L., Balmes, J., \& Adler, N. (2013). Social isolation: a predictor of mortality comparable to traditional clinical risk factors. American journal of public health, 103(11), 2056-2062.

Parke, R. D. (2004). Development in the family. Annu. Rev. Psychol., 55, 365-399. 
Pelini, S. (2019). How to Avoid Passing on Your Anxiety to Your Child. Psych Central. Retrieved on May 6, 2020, from https://psychcentral.com/blog/how-to-avoid-passing-on-your-anxiety-to-your-child/

Perissinotto, C. M., \& Covinsky, K. E. (2014). Living alone, socially isolated or lonely-What are we measuring? Journal of General Internal Medicine, 11, 1429-1431.

Ren, S. Y., Gao, R. D., \& Chen, Y. L. (2020). Fear can be more harmful than the severe acute respiratory syndrome coronavirus 2 in controlling the corona virus disease 2019 epidemic. World Journal of Clinical Cases, 8(4), 652.

Rimm, S. B. (2008). How to parent so children will learn: Strategies for raising happy, achieving children. Great Potential Press, Inc..

Rosenthal, T. L., \& Zimmerman, B. J. (2014). Social learning and cognition. Academic Press.

Rubin, G.J.; Potts, H.W.W.; Michie, S. The impact of communications about swine flu (influenza A H1N1v) on public responses to the outbreak: Results from 36 national telephone surveys in the UK. Health Technol. Assess. 2010, 14, 183-266.

Rubin, K. H., Asendorpf, J. B., \& Asendorpfz, J. (2014). Social withdrawal, inhibition, and shyness in childhood. Psychology Press.

Sanders, R. (2020). ESS Outline: Covid-19, social isolation and loneliness. Special Report Iriss.

Santini, Z. I., Koyanagi, A., Tyrovolas, S., Mason, C., \& Haro, J. M. (2015). The association between social relationships and depression: a systematic review. Journal of affective disorders, 175, 53-65.

Schonert-Reichl, K. A., Oberle, E., Lawlor, M. S., Abbott, D., Thomson, K., Oberlander, T. F., \& Diamond, A. (2015). Enhancing cognitive and social-emotional development through a simple-to-administer mindfulness-based school program for elementary school children: A randomized controlled trial. Developmental psychology, 51(1), 52.

Schunk, D. H., \& Zimmerman, B. J. (2012). Self-regulation and learning. Handbook of Psychology, Second Edition, 7.

Segerstrom, S. C. and Miller, G. E. (2004). Psychological Stress and the Human Immune System: A MetaAnalytic Study of 30 Years of Inquiry. Psychological Bulletin, Vol. 130, No. 4.

Seppala, E., Rossomando, T., \& Doty, J. R. (2013). Social connection and compassion: Important predictors of health and well-being. Social Research: An International Quarterly, 80(2), 411-430.

Shire, S. Y., Gulsrud, A., \& Kasari, C. (2016). Increasing responsive parent-child interactions and joint engagement: Comparing the influence of parent-mediated intervention and parent psychoeducation. Journal of autism and developmental disorders, 46(5), 1737-1747.

Shultz, J. M., Cooper, J. L., Baingana, F., Oquendo, M. A., Espinel, Z., Althouse, B. M., ... \& Mazurik, L. (2016). The role of fear-related behaviors in the 2013-2016 West Africa Ebola virus disease outbreak. Current psychiatry reports, 18(11), 104.

Siegenthaler, E., Munder, T., \& Egger, M. (2012). Effect of preventive interventions in mentally ill parents on the mental health of the offspring: systematic review and meta-analysis. Journal of the American Academy of Child \& Adolescent Psychiatry, 51(1), 8-17.

Simon, E. B., \& Walker, M. P. (2018). Sleep loss causes social withdrawal and loneliness. Nature communications, 9(1), 1-9. 
Stankovska, G., Memedi, I., \& Dimitrovsky, D. (2020). Coronavirus COVID-19 Disease, Mental Health and Psychological Support. Society Register, 4(2), 33-48.

Staub, E. (2013). Positive social behavior and morality: Socialization and development. Elsevier.

Steptoe, A., \& Kivimäki, M. (2012). Stress and cardiovascular disease. Nature Reviews Cardiology, 9(6), 360.

Steptoe, A., Owen, N., Kunz-Ebrecht, S. R., Brydon, L. (2004). Loneliness and neuroendocrine, cardiovascular, and inflammatory stress responses in middle-aged men and women. Psychoneuroendocrinology, 29(5). 593-611.

Stern, D. N. (2018). The interpersonal world of the infant: A view from psychoanalysis and developmental psychology. Routledge.

Stoica, A. M., \& Roco, M. (2013). The role of the emotional intelligence in kindergarden children's development. Procedia-Social and Behavioral Sciences, 78, 150-154.

Tamis-LeMonda, C. S., Shannon, J. D., Cabrera, N. J., \& Lamb, M. E. (2004). Fathers and mothers at play with their 2-and 3-year-olds: Contributions to language and cognitive development. Child development, 75(6), 1806-1820.

Teo, A. R., Lerrigo, R., \& Rogers, M. A. (2013). The role of social isolation in social anxiety disorder: A systematic review and meta-analysis. Journal of Anxiety Disorders, 27(4), 353-364.

Thomson, E., \& McLanahan, S. S. (2012). Reflections on "Family structure and child well-being: Economic resources vs. parental socialization". Social Forces, 91(1), 45-53.

Tomasello, M., \& Vaish, A. (2013). Origins of human cooperation and morality. Annual review of psychology, 64, 231-255.

Urbina-Garcia, M. A. (2019). Methodological Strategies to Listen to Children's Voices: A Systematic Critical Review. Revista Colombiana de Educación, (77), 61-85.

Valtorta, N. K., Kanaan, M., Gilbody, S., Ronzi, S., \& Hanratty, B. (2016). Loneliness and social isolation as risk factors for coronary heart disease and stroke: systematic review and meta-analysis of longitudinal observational studies. Heart, 102(13), 1009-1016.

van Ee, E., Kleber, R. J., \& Mooren, T. T. (2012). War trauma lingers on: Associations between maternal posttraumatic stress disorder, parent-child interaction, and child development. Infant mental health journal, 33(5), 459-468.

Woodruff-Borden, J., Morrow, C., Bourland, S., \& Cambron, S. (2002). The behavior of anxious parents: Examining mechanisms of transmission of anxiety from parent to child. Journal of Clinical Child and Adolescent Psychology, 31(3), 364-374.

Yeo, K., Frydenberg, E., Northam, E., \& Deans, J. (2014). Coping with stress among preschool children and associations with anxiety level and controllability of situations. Australian Journal of Psychology, 66(2), 93-101. 